\title{
Web-Crawling of Social Media to Analyze Backyard Poultry Owners Responses to the 2018-2020 Virulent Newcastle Disease (vND) Outbreak in Southern California
}

\author{
Maurice Pitesky ${ }^{1}$, Joseph Gendreau ${ }^{1}$, and Shayne Ramsubeik ${ }^{2}$ \\ ${ }^{1}$ University of California Davis Department of Population Health and Reproduction \\ ${ }^{2}$ California Animal Health and Food Safety Laboratory Turlock
}

August 4, 2021

\begin{abstract}
As social media becomes an ever-increasing staple of everyday life and a growing percentage of people turn to community driven platforms as a primary source of information, the data created from these posts can provide a new source of information from which to better understand an event in near real-time. The 2018-2020 outbreak of virulent Newcastle Disease (vND) in Southern California is the third outbreak of vND in Southern California within a 50-year time span. These outbreaks are thought to be primarily driven by non-commercial poultry (i.e. backyard and game fowl) in the region. Here we employed a commercial "web crawling" tool between June of 2018 and July of 2020 which encompassed the majority of the outbreak in order to collect all available online mentions of virulent Newcastle Disease (vND) in relation to the outbreak. A total of 2,498 posts in English and Spanish were returned using a Boolean logic-based string search. While the number of posts was relatively small, their impact as measured by the number of visitors to the website and the number of people viewing the post (where provided) was much larger. Using views as a metric, Twitter was identified as the most significant source of comments over blogs, forums and other news sites. Posts with negative sentiment were found to have a larger audience relative to posts with a positive sentiment. In addition, posts with negative sentiment peaked in May of 2019 which preceded the formation of the anti-depopulation group Save Our Birds (SOB). As the usage and impact of social media grows, the ability to utilize tools to analyze social media may improve both response and outreach-based strategies for various disease outbreaks including vND in Southern California which has a large non-commercial poultry population.
\end{abstract}

\section{Hosted file}

TBED_Final_B.docx available at https://authorea.com/users/429168/articles/532882-webcrawling-of-social-media-to-analyze-backyard-poultry-owners-responses-to-the-2018-2020virulent-newcastle-disease-vnd-outbreak-in-southern-california

\section{Hosted file}

Figure 1.docx available at https://authorea.com/users/429168/articles/532882-web-crawlingof-social-media-to-analyze-backyard-poultry-owners-responses-to-the-2018-2020-virulentnewcastle-disease-vnd-outbreak-in-southern-california

\section{Hosted file}

Figure 2.docx available at https://authorea.com/users/429168/articles/532882-web-crawlingof-social-media-to-analyze-backyard-poultry-owners-responses-to-the-2018-2020-virulentnewcastle-disease-vnd-outbreak-in-southern-california

\section{Hosted file}


Figure 3.docx available at https://authorea.com/users/429168/articles/532882-web-crawlingof-social-media-to-analyze-backyard-poultry-owners-responses-to-the-2018-2020-virulentnewcastle-disease-vnd-outbreak-in-southern-california 